Daniel J. Pallin

Ron M. Walls

\section{Letter to Cuthbertson et al.}

Accepted: 20 March 2010

Published online: 20 April 2010

(C) Copyright jointly held by Springer and ESICM 2010

An author's reply to this comment is available at:

doi:10.1007/s00134-010-1872-y.

To the editor: Cuthbertson et al. questioned the safety of single-dose etomidate, a valuable drug for intubation of patients with sepsis [1]. The fatal flaw in Cuthbertson's study was confounding by indication. Etomidate may have been chosen for sicker patients. The authors recommended that physicians enrolling patients in the study not use etomidate. Among induction agents, only etomidate and ketamine are considered hemodynamically safe. In light of the pressure not to use etomidate, physicians in this study probably chose etomidate only for the most unstable patients. From the authors: "Another possible explanation could be that etomidate was used more commonly in patients with higher severity of illness due to its improved cardiovascular stability... We do not know the patient's severity of illness at the time etomidate was used so cannot say to what degree their severity of illness on trial entry and subsequent outcome was directly influenced by etomidate use... Data on reasons for etomidate use were not collected" (our emphasis). This prospective observational study did not collect data on the most obvious potential confounder. How can a claim about the effects of etomidate be made when relevant baseline information was not collected at the right time?

The authors' theory is not a biologically plausible explanation for their observations. They acknowledge that the ability of etomidate to alter adrenocorticotropic hormone (ACTH) responsiveness lasts $<48 \mathrm{~h}$, yet the survival curves for etomidate versus no etomidate do not separate until 10 days after its administration.

The control variables used in the multivariate models were invalid. The Simplified Acute Physiology Score (SAPS) II and Sequential Organ Failure Assessment (SOFA) scores are collinear, because both scores assign points for renal failure, $\mathrm{PaO}_{2} /$ $\mathrm{FiO}_{2}$, hypotension, bilirubin, Glasgow Coma Scale, and malignancy $[2,3]$. This collinearity invalidates any model that includes them both. Of note, when they included only SAPS II in the model, the results were not significant (see Model 1 in Table 3).

The authors failed to adjust for multiple hypothesis testing - a critical requirement in a secondary analysis (especially when two models are shown, one insignificant and one borderline significant). The authors also overlook the rare disease assumption, required for reporting the odds ratio, which they should have converted to a relative risk, given that the outcome occurred in $33 \%$ of subjects [4].

In summary, this manuscript presents statistically nonsignificant results from a confounded design. Its conclusions rest upon an implausible causal model and multivariate analyses lacking face validity, and contradict a methodologically sound, randomized trial [5]. A single dose of etomidate for rapid sequence intubation is safe, and no one should hesitate to use it for fear of adrenal suppression.

\section{References}

1. Cuthbertson BH, Sprung CL, Annane D, Chevret S, Garfield M, Goodman S, Laterre PF, Vincent JL, Freivogel K, Reinhart K, Singer M, Payen D, Weiss YG (2009) The effects of etomidate on adrenal responsiveness and mortality in patients with septic shock. Intensive Care Med 35:1868-1876

2. Le Gall JR, Lemeshow S, Saulnier F (1993) A new Simplified Acute Physiology Score (SAPS II) based on a European/North American multicenter study. JAMA 270:2957-2963

3. Vincent JL, de Mendonca A, Cantraine F, Moreno R, Takala J, Suter PM, Sprung CL, Colardyn F, Blecher S (1998) Use of the SOFA score to assess the incidence of organ dysfunction/failure in intensive care units: results of a multicenter, prospective study. Working group on "sepsis-related problems" of the European Society of Intensive Care Medicine. Crit Care Med 26:1793-1800

4. Zhang J, Yu KF (1998) What's the relative risk? A method of correcting the odds ratio in cohort studies of common outcomes. JAMA 280:1690-1691

5. Jabre P, Combes X, Lapostolle F, Dhaouadi M, Ricard-Hibon A, Vivien B, Bertrand L, Beltramini A, Gamand P, Albizzati S, Perdrizet D, Lebail G, Chollet-Xemard C, Maxime V, BrunBuisson C, Lefrant JY, Bollaert PE, Megarbane B, Ricard JD, Anguel N, Vicaut E, Adnet F (2009) Etomidate versus ketamine for rapid sequence intubation in acutely ill patients: a multicentre randomised controlled trial. Lancet 374:293-300

D. J. Pallin $(\bowtie) \cdot$ R. M. Walls

Department of Emergency Medicine,

Brigham and Women's Hospital,

75 Francis St., Boston, MA 02115, USA

e-mail: dpallin@partners.org

D. J. Pallin

Division of Emergency Medicine,

Children's Hospital Boston,

Boston, MA, USA 